\title{
The posterior pedicle screw construct: 5-year results for thoracolumbar and lumbar curves
}

\author{
Presented at the 2013 Joint Spine Section Meeting
}

\section{Clinical article}

\author{
James T. Bennett, M.D., Jane S. Hoashi, M.D., M.P.H., Robert J. Ames, B.A., \\ Jeff S. Kimball, B.S., Joshua M. Pahys, M.D., and Amer F. Samdani, M.D.
}

\author{
Shriners Hospitals for Children, Philadelphia, Pennsylvania
}

\begin{abstract}
Object. Several studies of the outcomes of patients with adolescent idiopathic scoliosis (AIS) with thoracolumbar and lumbar curves after treatment with posterior pedicle screws have been reported, but most of these studies reported only 2-year follow-up. The authors analyzed the radiographic and clinical outcomes of patients with thoracolumbar and lumbar curves treated with posterior pedicle screws after 5 years of follow-up.

Methods. A multicenter database was retrospectively queried to identify patients with AIS who underwent spinal fusion for Lenke 3C, 5C, and 6C curves. Radiographs from the following times were compared: preoperative, first follow-up visit, 1-year follow-up visit, 2-year follow-up visit, and 5-year follow-up visit. Chart review included scoliometer measurements, Scoliosis Research Society (SRS)-22 questionnaires, and complications requiring return to the operating room.

Results. Among 26 patients with Lenke 3C, 5C, and 6C curves, the mean ( \pm SD) age was $14.6 \pm 2.1$ years. From the time of the preoperative radiographs to the 5-year follow-up radiographs, there was a statistically significant improvement in the mean coronal lumbar Cobb angles $(\mathrm{p}<0.0001)$, and from the time of the first postoperative radiographs to the 5-year follow-up radiographs, the lumbar curve remained stable $(p=0.14)$. From the time of the preoperative radiographs to the 5-year follow-up radiographs, there was a statistically significant improvement in the mean coronal thoracic Cobb angles $(\mathrm{p}<0.0001)$, and from the time of the first postoperative radiographs to the 5 -year follow-up radiographs, the thoracic curve remained stable $(\mathrm{p}=0.10)$. From the first postoperative visit to the 5 -year follow-up visit, the thoracic kyphosis $(\mathrm{T} 5-12)$ remained stable $(\mathrm{p}=0.10)$, and from the time of the preoperative radiographs to the 5-year follow-up radiographs, the lumbar lordosis (T-12 to top of sacrum) remained stable ( $\mathrm{p}=$ $0.44)$. From the preoperative visit to the 5 -year follow-up visit, the coronal balance improved significantly $(p<0.05)$ and remained stable from the first postoperative visit to the 5-year follow-up visit $(p=0.20)$. The SRS-22 total scores improved significantly from before surgery to 5 years after surgery $(\mathrm{p}<0.0001)$. No patients required reoperation because of complications.

Conclusions. Correction of the coronal, sagittal, and axial planes in this cohort of patients was maintained from the first follow-up measurements to 5 years after surgery. In addition, at 5 years after surgery total SRS-22 scores and inclinometer readings were improved from preoperative scores and measurements.

(http://thejns.org/doi/abs/10.3171/2013.8.SPINE12816)
\end{abstract}

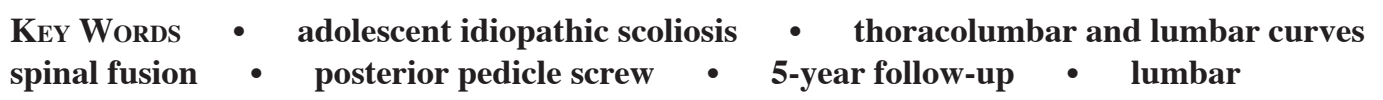

$\mathrm{T}$ Jwo approaches (anterior and posterior) are used for the treatment of thoracolumbar and lumbar adolescent idiopathic scoliosis (AIS). 2,6,7,9,12,13,16,20-22 In 1969, Dwyer et al. first proposed the anterior approach for the treatment of thoracolumbar and lumbar curves with use of vertebral body screws and a compression cable. This approach resulted in good coronal correction but also resulted in a kyphosing effect, poor derotation, and a high rate of pseudarthrosis. ${ }^{6,7,12,16}$ Later, to improve derotation, Zielke replaced the wires with an anterior

\footnotetext{
Abbreviations used in this paper: AIS = adolescent idiopathic scoliosis; SRS $=$ Scoliosis Research Society.
}

threaded rod, but the kyphosing effect and high rate of pseudarthrosis remained.2,13 Later, dual anterior solid rods were developed and resulted in better coronal correction, improved derotation, and less kyphosis. ${ }^{21}$

The first posterior approach to be accepted for treatment of thoracolumbar and lumbar AIS was the Harrington method, which used posterior hooks and rods. ${ }^{9}$ In 1989, Luk et al. compared the Harrington, Dwyer, and Zielke methods and showed improved correction in the coronal and sagittal planes with posterior hooks and rods. ${ }^{20}$ In 2004, Shufflebarger et al. showed that using a wide posterior release and posterior pedicle screws to correct lumbar and thoracolumbar idiopathic scoliosis 


\section{Posterior pedicle screw construct}

resulted in a coronal correction of $80 \%$ with good sagittal alignment at 2 years after surgery. ${ }^{22}$ Several studies that compared anterior spinal fusion with pedicle screw fixation for the treatment of thoracolumbar and lumbar AIS reported no statistically significant difference in coronal or sagittal curve correction between the 2 methods at 2 years after surgery. ${ }^{10,19,25}$ However, in 2009, Geck et al. compared patients with Lenke 5C AIS treated with a posterior release and pedicle screws with those who received anterior instrumentation; they found that at 2 years after surgery, the patients with pedicle screws had statistically significantly better curve corrections, better maintenance of corrections over time, and shorter hospital stays. ${ }^{8}$

Although the long-term results for anterior constructs have been reported, clinical and radiographic outcomes of pedicle screw constructs are largely based on short-term follow-up. To our knowledge, no study has examined radiographic findings, progression, and clinical outcomes of patients with thoracolumbar and lumbar AIS curves treated with pedicle screw constructs for a minimum of 5 years after surgery.

\section{Methods}

Institutional Review Board approval for the study was obtained locally from each contributing institution's review board, and consent was obtained from each patient before data collection. A prospectively collected multicenter database was retrospectively reviewed to identify 99 patients (younger than 18 years) with AIS treated with pedicle screws from January 2002 to December 2006 and followed for at least 5 years. Patients with Lenke 1,2, and 4 curves were excluded, leaving 26 patients with Lenke 3C, 5C, and 6C AIS. Lenke 3C curves were included because they have a structural thoracolumbar component.

Standing posteroanterior and lateral radiographs were taken preoperatively and at the first follow-up visit and 1,2, and 5 years after surgery. The following measurements were recorded from the radiographs: coronal lumbar and thoracic curve magnitudes, percentage flexibility (measured on side-bending radiographs), coronal balance (distance between $\mathrm{C}-7$ and the central sacral vertical line), thoracic kyphosis (T5-12), and lumbar lordosis (T-12 to the top of the sacrum). To reduce radiation exposure and because we did not suspect malpositioned screws or pseudarthrosis, we did not obtain CT scans. Other study variables were Lenke classification, Scoliosis Research Society (SRS)-22 scores, angle of rotation as measured by scoliometer, fusion levels, and postoperative complications. Statistical analyses were performed using the SPSS statistical package (version 12.0.2, SPSS, Inc.). All results are reported as means \pm standard deviations. Descriptive statistical analyses were performed using ANOVA and were used to detect differences between the time periods; significance level was 0.05 .

\section{Results \\ Patient Demographics \\ The cohort consisted of 26 patients with thoracolum- bar or lumbar AIS (6 patients with Lenke 3C, 8 with Lenke}

$5 \mathrm{C}$, and 12 with Lenke $6 \mathrm{C}$ ). The mean age of the patients was $14.6 \pm 2.1$ years, and $24(92 \%)$ were female (Table 1).

\section{Thoracolumbar/Lumbar Curve}

The mean $( \pm \mathrm{SD})$ preoperative lumbar coronal Cobb angle was $55.4^{\circ} \pm 12.1^{\circ}$, straightening to $27.5^{\circ} \pm 12.1^{\circ}$ on side-bending radiographs, for a mean lumbar percentage flexibility of $50.0 \% \pm 20.0 \%$. From the time of the preoperative radiographs to the 5-year follow-up radiographs, there was a statistically significant improvement of the mean coronal lumbar Cobb angles ( $p<0.0001)$, and from the time of the first postoperative radiographs to the 5-year follow-up radiographs, the curve remained stable $(\mathrm{p}=0.14)$. Furthermore, at the first postoperative visit, the mean percentage correction of the lumbar curve was $70.0 \% \pm 20.0 \%$, and it remained the same at the 1-, 2-, and 5-year follow-up visits (Table 2).

\section{Thoracic Curve}

The mean preoperative thoracic coronal Cobb angle was $46.4^{\circ} \pm 19.6^{\circ}$, straightening to $30.1^{\circ} \pm 16.4^{\circ}$ on sidebending radiographs, for a mean thoracic percentage flexibility of $40.0 \% \pm 20.0 \%$. From the time of the preoperative radiographs to the 5-year follow-up radiographs, there was a statistically significant improvement of the mean coronal thoracic Cobb angles ( $p<0.0001)$, and from the time of the first postoperative visit to the 5-year followup visit, the curve remained stable $(\mathrm{p}=0.10)$. However, the thoracic mean percent curve correction decreased significantly from the first postoperative visit to the 5-year follow-up visit $(\mathrm{p}<0.05)$ (Table 2$)$.

\section{Thoracic Kyphosis and Lumbar Lordosis}

From the preoperative visit to the 5-year follow-up visit, there was a statistically significant decrease of the mean thoracic kyphosis (T5-12) $(\mathrm{p}<0.05)$. However, from the first follow-up visit to the 5-year follow-up visit, the mean thoracic kyphosis (T5-12) remained stable ( $p$ $=0.10$ ). From the preoperative visit to the 5-year followup visit, the mean lumbar lordosis (T-12 to the top of the sacrum) remained stable $(\mathrm{p}=0.44)$ (Table 2$)$.

\section{Coronal Balance}

From the preoperative visit to the 5-year follow-up visit, the mean coronal balance $(\mathrm{C}-7$ to the central sacral vertical line) improved significantly $(\mathrm{p}<0.05)$. From the

\section{TABLE 1: Demographics for the 26 patients*}

\begin{tabular}{cc}
\hline Characteristic & No. of Patients \\
\hline sex & 24 \\
female & 2 \\
male & \\
Lenke curve (type) & 6 \\
3C & 8 \\
5C & 12 \\
6C
\end{tabular}

\footnotetext{
* Mean age $14.6 \pm 2.1$ years.
} 
TABLE 2: Radiographic measurements of thoracic and thoracolumbar/lumbar curves*

\begin{tabular}{|c|c|c|c|c|c|c|}
\hline Measurement ${ }^{\star}$ & Preop & 1st Postop & 1-Yr Postop & 2-Yr Postop & 5-Yr Postop & $\mathrm{p}$ Value \\
\hline thoracolumbar/lumbar Cobb & $55.4 \pm 12.1$ & $14.7 \pm 9.4$ & $15.7 \pm 8.5$ & $15.7 \pm 9.4$ & $17.3 \pm 10.0$ & $<0.0001$ \\
\hline thoracic Cobb & $46.4 \pm 19.6$ & $14.4 \pm 7.3$ & $16.5 \pm 7.5$ & $16.3 \pm 7.4$ & $17.4 \pm 7.9$ & $<0.0001$ \\
\hline thoracic kyphosis (T5-12) & $27.7 \pm 10.1$ & $24.6 \pm 8.4$ & $23.8 \pm 8.1$ & $22.8 \pm 10.4$ & $23.1 \pm 12.7$ & $<0.05$ \\
\hline lumbar lordosis (T12-top of sacrum) & $-60.0 \pm 13.2$ & $-54.7 \pm 12.4$ & $-61.3 \pm 13.3$ & $-56.7 \pm 12.4$ & $-58.2 \pm 13.4$ & 0.44 \\
\hline coronal balance (C7-CSVL) $(\mathrm{cm} \pm \mathrm{SD})$ & $-1.7 \pm 2.8$ & $-1.3 \pm 2.7$ & $-1.3 \pm 2.7$ & $-0.7 \pm 1.4$ & $-0.8 \pm 0.9$ & $<0.05$ \\
\hline
\end{tabular}

* All measurements are in degrees \pm SD unless otherwise indicated. CSVL = central sacral vertical line.

$\dagger$ Preoperative to 5-year postoperative. Boldface indicates statistical significance.

first postoperative visit to the 5-year follow-up visit, it remained stable $(\mathrm{p}=0.20)$ (Table 2$)$.

\section{Inclinometer Readings}

From the preoperative visit to the 5-year follow-up visit, the thoracic and lumbar inclinometer measurements revealed significant improvement $(\mathrm{p}<0.0001)$. These measurements remained stable from 1 year to 5 years after surgery $(\mathrm{p}=0.19)$ (Table 3$)$.

\section{SRS-22 Scores}

From the preoperative visit to the 5-year follow-up visit, SRS-22 total scores improved significantly ( $p<$ 0.0001). In particular, patients experienced statistically significant improvements in self-image and satisfaction $(\mathrm{p}<0.0001)$ (Table 4).

\section{Postoperative Complications}

Overall, 7 (26.9\%) of the 26 patients experienced minor postoperative complications; 5 patients within 60 days of surgery and 2 patients after 60 days of surgery. Among those with early complications, 1 patient experienced a urinary tract infection on postoperative Day 0, which resolved without antibiotic therapy; 1 patient experienced gastrointestinal ileus on postoperative day 6 , which resolved after intravenous hydration and an enema; 2 patients experienced postoperative numbness over the right chest on postoperative Days 0 and 46, which resolved without treatment; and 1 patient experienced a small pleural effusion on postoperative Day 24, which resolved without treatment. Among those with late complications, 1 patient experienced pain caused by prominent hardware on postoperative Day 814, which resolved after an injection of bupivacaine and triamcinolone; and 1 patient experienced 2 episodes of sciatica of the right lower extremity on postoperative Day 2274 , which resolved after physical therapy. No patients experienced proximal junctional kyphosis, residual deformity, pseudarthrosis, malpositioned instrumentation, hardware failure, or infection that required a return to the operating room (Table 5).

\section{Discussion}

Several studies have reported the outcomes of patients with thoracolumbar and lumbar AIS treated with pedicle screw constructs, ${ }^{8,10,17-19,22,25}$ however, most of these studies reported only 2 years of follow-up. To the best of our knowledge, ours is the first such study to analyze the clinical and radiographic findings of posterior pedicle screw constructs at 5 years after surgery. Overall, our results suggest that from the first follow-up visit to the 5-year follow-up visit, the coronal, sagittal, and axial plane correction measurements were maintained. Furthermore, at the 5-year follow-up visit, SRS-22 total scores and inclinometer readings were improved over preoperative scores and readings.

The long-term outcomes of older posterior spinal fusion constructs and anterior spinal fusions for the treatment of AIS have been well documented., $, 3,4,11,14,24$ However, long-term data on the pedicle screw construct are limited. . $3,4,15,23$ In 2005, Suk et al. studied 203 patients with AIS who underwent segmental thoracic pedicle screw fixation; they reported a $69 \%$ correction of the main thoracic curve and a $66 \%$ correction of the compensatory lumbar curve and good maintenance of the sagittal profile at 5 years after surgery. ${ }^{23}$ Di Silvestre et al. compared pedicle screw and posterior hybrid constructs among 52 patients with AIS for a mean of 6.7 years of follow-up and found better maintenance of the main thoracic curve correction with pedicle screws (mean loss of $11.3^{\circ}$ with hybrid constructs compared with mean loss of $1.9^{\circ}$ with pedicle screws)..$^{5}$

In 2004, Shufflebarger et al. reported the outcomes of patients with Lenke $3 \mathrm{C}, 5$, and 6 AIS curves after treatment with a wide posterior release and pedicle screw fixation; they reported $80 \%$ coronal plane correction with normalization of the sagittal plane, leveling of the lowest

TABLE 3: Inclinometer readings

\begin{tabular}{|c|c|c|c|c|c|}
\hline \multirow[b]{2}{*}{ Location } & \multicolumn{4}{|c|}{ Degrees \pm SD } & \multirow[b]{2}{*}{$p$ Value* } \\
\hline & Preop & 1-Yr Postop & 2-Yr Postop & 5-Yr Postop & \\
\hline thoracic & $10.5 \pm 5.3$ & $7.1 \pm 4.8$ & $6.8 \pm 3.9$ & $5.7 \pm 3.9$ & $<0.0001$ \\
\hline lumbar & $12.6 \pm 5.4$ & $3.3 \pm 3.1$ & $3.1 \pm 3.4$ & $2.6 \pm 3.3$ & $<0.0001$ \\
\hline
\end{tabular}

* Preoperative to 5 -year postoperative. Boldface indicates statistical significance. 


\section{Posterior pedicle screw construct}

instrumented vertebra, and improved balance parameters at 2 years after surgery. ${ }^{22}$ Our study shows similar findings at 5 years; thoracolumbar/lumbar percent correction was maintained at $70.0 \% \pm 20.0 \%$, and the thoracic Cobb angle was maintained, but the thoracic percent correction decreased significantly from the first postoperative visit to the 5-year follow-up visit. Thoracic kyphosis (T5-12) also decreased significantly from the preoperative visit to the first postoperative follow-up visit. However, from the first follow-up visit to the 5-year follow-up visit, the mean thoracic kyphosis values remained stable with excellent preservation of lumbar lordosis (T-12 to the top of the sacrum). These minor differences between our study and the Shufflebarger et al. study may be the result of the longer follow-up period (5 years vs 2 years), larger preoperative thoracic coronal Cobb angles (mean $46.4^{\circ} \pm 19.6^{\circ}$ vs $27^{\circ}$ for Lenke 5 and $43^{\circ}$ for Lenke $3 \mathrm{C}$ and 6 curves), and larger preoperative lumbar mean coronal $\mathrm{Cobb}$ angles $\left(55.4^{\circ} \pm 12.1^{\circ}\right.$ vs $\left.52^{\circ}\right)$ found in our study.

Most importantly, from 2 to 5 years after surgery, no significant radiographic changes, including thoracic and thoracolumbar/lumbar coronal Cobb magnitudes, thoracic kyphosis (T5-12), lumbar lordosis (T-12 to the top of the sacrum), and coronal balance, were found (Fig. $1 \mathrm{~A}-\mathrm{H})$. The inclinometer readings also did not differ significantly from 2 to 5 years after surgery. This finding is
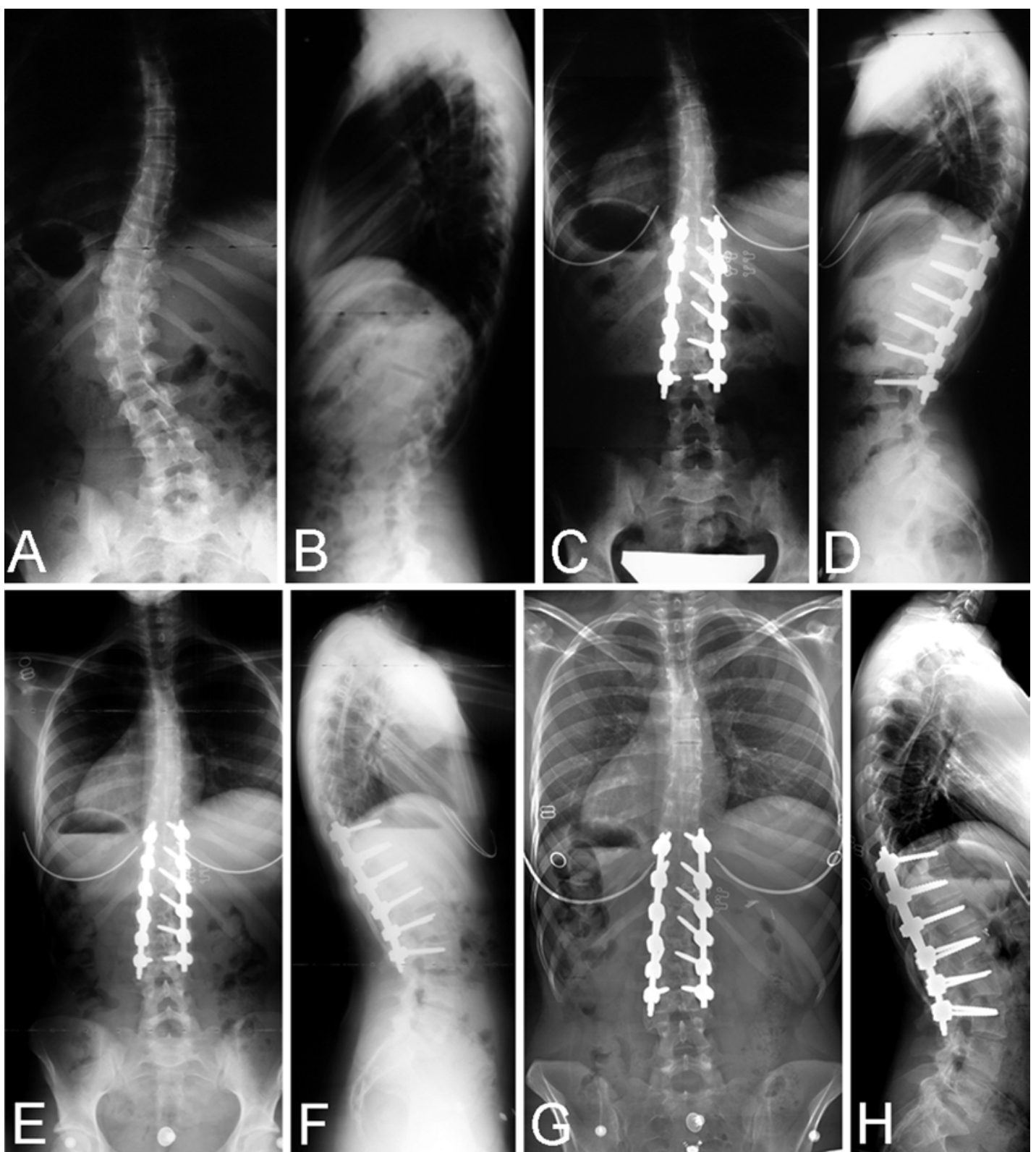

FIG. 1. Preoperative standing posteroanterior (A) and lateral (B) radiographs obtained in a 15 -year-old girl with a left $48^{\circ}$ main thoracolumbar curve and a $29^{\circ}$ compensatory thoracic curve. First erect posteroanterior (C) and lateral (D) radiographs obtained after selective posterior spinal fusion with pedicle screws from T-10 to L-3, showing a 2-cm coronal (C7-central sacral vertical line) imbalance to the left. Two-year follow-up posteroanterior $(\mathbf{E})$ and lateral $(\mathbf{F})$ radiographs showing restoration of coronal balance. Five-year follow-up posteroanterior $(\mathbf{G})$ and lateral $(\mathrm{H})$ radiographs showing maintenance of coronal and sagittal correction. 
TABLE 4: SRS-22 scores

\begin{tabular}{lccc}
\hline \multirow{2}{*}{ Domain } & \multicolumn{2}{c}{ Score \pm SD } & \\
\cline { 2 - 3 } \multicolumn{1}{c}{ Preop } & 5 -yr Postop & p Value* \\
\hline pain & $4.0 \pm 0.7$ & $4.3 \pm 0.7$ & 0.069 \\
self-image & $3.2 \pm 0.6$ & $4.4 \pm 0.7$ & $<0.0001$ \\
general function & $4.5 \pm 0.7$ & $4.7 \pm 0.5$ & 0.160 \\
mental health & $3.9 \pm 0.8$ & $4.0 \pm 0.9$ & 0.380 \\
satisfaction & $3.2 \pm 1.1$ & $4.6 \pm 0.7$ & $<0.0001$ \\
total & $3.8 \pm 0.5$ & $4.3 \pm 0.6$ & $<0.0001$ \\
\hline
\end{tabular}

* Boldface indicates statistical significance.

clinically relevant and reassuring, especially when counseling patients about the likelihood that their curve correction will remain stable from 2 to 5 years after surgery.

The study was limited because it had a small sample size (26 patients). Furthermore, the study was a retrospective review of a multicenter database reflecting different surgeons and surgical techniques. However, use of a multicenter database was necessary to obtain the greatest sample size. Although there are some data on 5-year results of thoracolumbar and lumbar AIS treated with posterior pedicle screw constructs, there are no published radiographic or clinical data on 10-year outcomes. For better evaluation of the progression and incidence of long-term clinical outcomes for thoracolumbar and lumbar AIS treated with posterior pedicle screw constructs, longer follow-up is required.

\section{Conclusions}

Radiographs obtained in 26 patients with thoracolumbar and lumbar AIS curves treated with posterior pedicle screw constructs revealed that the coronal, sagittal, and axial plane corrections noted at the first postoperative followup visit were maintained 5 years later. The SRS-22 total scores and inclinometer readings were better 5 years after surgery than they had been before surgery.

\section{Disclosure}

Dr. Samdani is a consultant for DePuy Synthes Spine, SpineGuard,Zimmer, and Stryker. This study was supported by a research

\section{TABLE 5: Postoperative complications}

\begin{tabular}{ll}
\hline \multicolumn{1}{c}{ Complications } & No. $(\%)$ \\
\hline total & $7(26.9)$ \\
early $(<60$ days) & $5(19.2)$ \\
urinary tract infection & $1(3.8)$ \\
neurological & $2(7.7)$ \\
gastrointestinal ileus & $1(3.8)$ \\
pleural effusion & $1(3.8)$ \\
late $(\geq 60$ days) & $2(7.7)$ \\
prominent hardware & $1(3.8)$ \\
neurological & $1(3.8)$ \\
\hline
\end{tabular}

grant from DePuy Spine to the Setting Scoliosis Straight Foundation of the Harms Study Group.

Author contributions to the study and manuscript preparation include the following. Conception and design: Samdani. Acquisition of data: Bennett, Hoashi, Ames, Kimball. Analysis and interpretation of data: Bennett. Drafting the article: Bennett. Critically revising the article: all authors. Reviewed submitted version of manuscript: all authors. Approved the final version of the manuscript on behalf of all authors: Samdani. Study supervision: Samdani.

\section{References}

1. Andersen MO, Christensen SB, Thomsen K: Outcome at 10 years after treatment for adolescent idiopathic scoliosis. Spine (Phila Pa 1976) 31:350-354, 2006

2. Bernstein RM, Hall JE: Solid rod short segment anterior fusion in thoracolumbar scoliosis. J Pediatr Orthop B 7:124131,1998

3. Bjerkreim I, Steen H, Brox JI: Idiopathic scoliosis treated with Cotrel-Dubousset instrumentation: evaluation 10 years after surgery. Spine (Phila Pa 1976) 32:2103-2110, 2007

4. Cochran T, Irstam L, Nachemson A: Long-term anatomic and functional changes in patients with adolescent idiopathic scoliosis treated by Harrington rod fusion. Spine (Phila Pa 1976) 8:576-584, 1983

5. Di Silvestre M, Bakaloudis G, Lolli F, Vommaro F, Martikos K, Parisini P: Posterior fusion only for thoracic adolescent idiopathic scoliosis of more than 80 degrees: pedicle screws versus hybrid instrumentation. Eur Spine J 17:1336-1349, 2008

6. Dwyer AF, Newton NC, Sherwood AA: An anterior approach to scoliosis. A preliminary report. Clin Orthop Relat Res 62: 192-202, 1969

7. Dwyer AF, Schafer MF: Anterior approach to scoliosis. Results of treatment in fifty-one cases. J Bone Joint Surg Br 56: 218-224, 1974

8. Geck MJ, Rinella A, Hawthorne D, Macagno A, Koester L, Sides B, et al: Comparison of surgical treatment in Lenke 5C adolescent idiopathic scoliosis: anterior dual rod versus posterior pedicle fixation surgery: a comparison of two practices. Spine (Phila Pa 1976) 34:1942-1951, 2009

9. Harrington PR: Treatment of scoliosis. Correction and internal fixation by spine instrumentation. J Bone Joint Surg Am 44-A:591-610, 1962

10. Hee HT, Yu ZR, Wong HK: Comparison of segmental pedicle screw instrumentation versus anterior instrumentation in adolescent idiopathic thoracolumbar and lumbar scoliosis. Spine (Phila Pa 1976) 32:1533-1542, 2007

11. Helenius I, Remes V, Yrjönen T, Ylikoski M, Schlenzka D, Helenius M, et al: Harrington and Cotrel-Dubousset instrumentation in adolescent idiopathic scoliosis. Long-term functional and radiographic outcomes. J Bone Joint Surg Am 85-A: 2303-2309, 2003

12. Hsu LC, Zucherman J, Tang SC, Leong JC: Dwyer instrumentation in the treatment of adolescent idiopathic scoliosis. J Bone Joint Surg Br 64:536-541, 1982

13. Kaneda K, Fujiya N, Satoh S: Results with Zielke instrumentation for idiopathic thoracolumbar and lumbar scoliosis. Clin Orthop Relat Res (205):195-203, 1986

14. Kelly DM, McCarthy RE, McCullough FL, Kelly HR: Longterm outcomes of anterior spinal fusion with instrumentation for thoracolumbar and lumbar curves in adolescent idiopathic scoliosis. Spine (Phila Pa 1976) 35:194-198, 2010

15. Kim YJ, Lenke LG, Kim J, Bridwell KH, Cho SK, Cheh G, et al: Comparative analysis of pedicle screw versus hybrid instrumentation in posterior spinal fusion of adolescent idiopathic scoliosis. Spine (Phila Pa 1976) 31:291-298, 2006

16. Kohler R, Galland O, Mechin H, Michel CR, Onimus M: The Dwyer procedure in the treatment of idiopathic scoliosis. 


\section{Posterior pedicle screw construct}

A 10-year follow-up review of 21 patients. Spine (Phila Pa 1976) 15:75-80, 1990

17. Li J, Hwang SW, Shi Z, Yan N, Yang C, Wang C, et al: Analysis of radiographic parameters relevant to the lowest instrumented vertebrae and postoperative coronal balance in Lenke 5C patients. Spine (Phila Pa 1976) 36:1673-1678, 2011

18. Li M, Fang X, Sun Y, Wang X, Wang L, Liu H, et al: Thoracic curve correction after posterior fusion and instrumentation of structural lumbar curves in patients with adolescent idiopathic scoliosis. Arch Orthop Trauma Surg 131:1375-1381, 2011

19. Li M, Ni J, Fang X, Liu H, Zhu X, He S, et al: Comparison of selective anterior versus posterior screw instrumentation in Lenke5C adolescent idiopathic scoliosis. Spine (Phila Pa 1976) 34:1162-1166, 2009

20. Luk KD, Leong JC, Reyes L, Hsu LC: The comparative results of treatment in idiopathic thoracolumbar and lumbar scoliosis using the Harrington, Dwyer, and Zielke instrumentations. Spine (Phila Pa 1976) 14:275-280, 1989

21. Sanders AE, Baumann R, Brown H, Johnston CE II, Lenke LG, Sink E: Selective anterior fusion of thoracolumbar/lumbar curves in adolescents: when can the associated thoracic curve be left unfused? Spine (Phila Pa 1976) 28:706-714, 2003

22. Shufflebarger HL, Geck MJ, Clark CE: The posterior approach for lumbar and thoracolumbar adolescent idiopathic scoliosis: posterior shortening and pedicle screws. Spine (Phila Pa 1976) 29:269-276, 2004

23. Suk SI, Lee SM, Chung ER, Kim JH, Kim SS: Selective thoracic fusion with segmental pedicle screw fixation in the treatment of thoracic idiopathic scoliosis: more than 5-year followup. Spine (Phila Pa 1976) 30:1602-1609, 2005

24. Tis JE, O'Brien MF, Newton PO, Lenke LG, Clements DH, Harms J, et al: Adolescent idiopathic scoliosis treated with open instrumented anterior spinal fusion: five-year follow-up. Spine (Phila Pa 1976) 35:64-70, 2010

25. Wang Y, Fei Q, Qiu G, Lee CI, Shen J, Zhang J, et al: Anterior spinal fusion versus posterior spinal fusion for moderate lumbar/thoracolumbar adolescent idiopathic scoliosis: a prospective study. Spine (Phila Pa 1976) 33:2166-2172, 2008

Manuscript submitted January 14, 2013.

Accepted August 13, 2013.

Please include this information when citing this paper: published online September 27, 2013; DOI: 10.3171/2013.8.SPINE12816.

Address correspondence to: Amer F. Samdani, M.D., Shriners Hospitals for Children, 3551 N. Broad St., Philadelphia, PA 19140. email: amersamdani@gmail.com. 